\section{Runway performance of goldfish as a function of complete and incomplete reduction in amount of reward*}

\author{
R. C. GONZALEZ, ALCINE POTTS, and KATHERINE PITCOFF \\ Bryn Mawr College, Bryn Mawr, Pa. 19010 \\ and \\ M. E. BITTERMAN \\ University of Hawaii, Honolulu, Hawaii 96822
}

Two experiments are reported in which goldfish failed to show the inverse relation between resistance to extinction and amount of reward and failed also to show the depression effect under conditions analogous to those which most clearly produce these effects in rats.

The results of a recent series of experiments with rats trained in a runway (Gonzalez \& Bitterman, 1969) suggest that the inverse relation between resistance to extinction and amount of reward (e.g., Hulse, 1958; Wagner, 1961) is the product of the operation in Ss extinguished after training with large reward of the same process which produces the depression effect in Ss shifted to a small reward after training with large reward (Crespi, 1942).

The results of several experiments with goldfish trained in a keypressing situation are consistent with the contrast interpretation of the extinction effect in rats. Two of the experiments were performed under conditions of massed practice, one in a free operant situation (Gonzalez, Holmes, \& Bitterman, 1967) and the other in discrete trials (Gonzalez \& Bitterman, 1967); in each, the fish showed a positive relation between resistance to extinction and amount of reward. In a third experiment, performed at the rate of one trial per day and patterned after that of Crespi, the fish failed to show the depression effect (Lowes \& Bitterman, 1967), an outcome which was anticipated on the basis of the results of the two experiments on resistance to extinction. The possibility should be considered, however, that the failure of the fish to show the depression effect was the product simply of a set of conditions under which the effect might also fail to appear in rats. Denny (1959), for example, found that rats trained in a leverpressing situation at the rate of one trial per day showed no deterioration whatsoever in

*This work, done at Bryn Mawr College, was supported by Grants 02857 and 15902 from NIMH. Requests for reprints should be sent to R. C. Gonzalez, Department of Psychology, Bryn Mawr College. Bryn Mawr, Pa. 19010. performance in the course of 75 extinction trials. The failure of the goldfish to show the depression effect took a similar form: there was no decrement at all in their performance with the downshift in magnitude of reward.

The experiments to be reported here were intended to extend the study of the behavior of fish to the conditions under which rats most clearly show both the depression effect and the inverse relation between resistance to extinction and amount of reward: widely spaced trials in the runway.

\section{EXPERIMENT 1}

The aims of this experiment were to establish functionally distinct levels of reward magnitude and to determine the effect of this variable on resistance to extinction in fish given one trial per day in a runway.

$$
\text { Subjects }
$$

The Ss were 42 experimentally naive goldfish, 4-5 in. long, obtained from a local dealer. They were maintained in individual 2-gal tanks set on open shelves in a temperature-controlled laboratory.

$$
\text { Apparatus }
$$

The apparatus, which has been described in detail elsewhere (Potts \& Bitterman, 1968), was a runway with a start compartment (12 in. long), an alley ( $3 \mathrm{ft}$ long), and a goal compartment (10.5 in. long). The goal compartment was fixed at a 90-deg angle to the end of the alley and entered by a left turn. The entire unit was made of black Plexiglas, with walls 6 in. high, and had hinged lids made of diffusing Plexiglas. It was filled with water to a depth of 4 in. A guillotine door $\left(D_{1}\right)$ controlled entrance into the alley from the start compartment. A second guillotine door $\left(D_{2}\right)$ prevented retracing from the goal compartment. The opening of $D_{1}$ by $E$ tripped a microswitch mounted on the door frame which activated three Standard
Electric timers. The first timer was stopped by S's interruption of a light beam 2 in. beyond $D_{1}$, yielding a measure of start time; the second timer was stopped by S's interruption of a second light beam 6 in. before $D_{2}$, yielding a measure of start plus runway time; the third timer was stopped by S's interruption of a third light beam 2 in. beyond the left turn in the goal compartment, yielding a measure of total time. On reinforced trials, interruption of the third beam also activated a feeder which discharged live Tubifex worms into the far end of the goal compartment through a small opening in the lid.

\section{PROCEDURE}

The Ss were placed on a 24-h feeding schedule of dry food and, after adjustment to the laboratory, were given experience with Tubifex worms introduced into their home tanks with a medicine dropper. There were 5 days of adjustment to handling, on each of which S was scooped up from its home tank in a small container of clear Plexiglas, carried to the area of the room in which the runway was located, and then returned to its home tank and fed Tubifex worms. On each of the following 3 days, $S$ was carried in the Plexiglas container to the goal compartment and confined there until it had eaten a prescribed number of worms discharged from the feeder. For 14 randomly selected Ss, these goal compartment feedings were of 1 worm each; for another 14 randomly selected Ss, they were of 4 worms each; for the remaining $14 \mathrm{Ss}$, they were of 40 worms each.

In the first stage of the experiment proper, which lasted 24 days, each $S$ was given one reinforced trial per day in the runway. Group 1 was reinforced with 1 worm, Group 4 with 4 worms, and Group 40 with 40 worms. On each trial, $S$ was placed in the start compartment with $D_{1}$ closed and $D_{2}$ open. The trial began 5 sec later, with the opening of $\mathrm{D}_{1}$ by $\mathrm{E}$, and ended with the interruption of the third light beam by $S$, after which $E$ closed $D_{2} . S$ was scooped out of the goal compartment as soon as it had eaten the food and returned to its living tank. In the second stage of the experiment, which lasted 39 days, all trials were unreinforced. The procedure on each trial was the same as in the first stage, with the exception that the feeder did not operate, and $S$ was removed from the goal compartment $20 \mathrm{sec}$ after having entered it. If, on any trial, $S$ did not enter the goal compartment within $5 \mathrm{~min}$, the trial was terminated, both doors were lowered, and $S$ was removed from the apparatus and returned to its home tank. Throughout the experiment, the total daily ration 


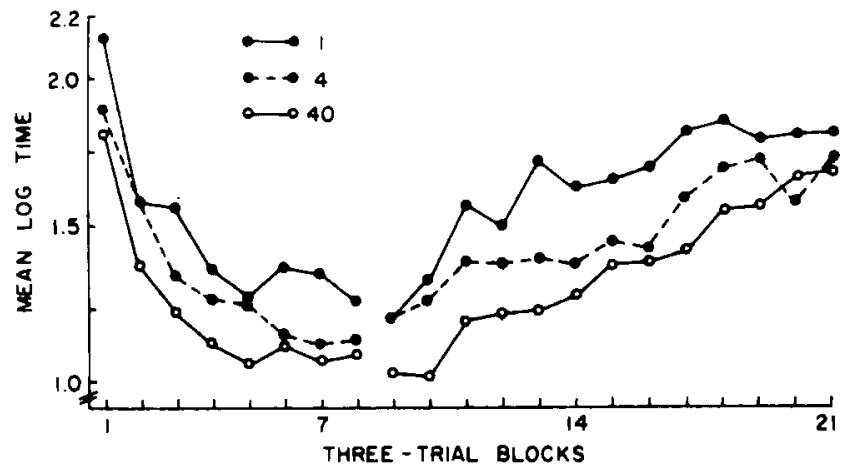

Fig. 1. Acquisition and extinction in spaced trials as a function of amount of reward.

of food for all Ss was 42 worms plus a small amount of dry food. That portion not earned in the apparatus was postfed in S's living tank $30 \mathrm{~min}$ after each day's trial.

\section{Results}

In Fig. 1, the course of acquisition and extinction is shown for each of the groups in terms of mean log total time for three-trial blocks. In acquisition, the three curves declined in negatively accelerated fashion to terminal levels ordered in terms of amount of reward. (Four Ss were lost in the course of the experiment, two each from the 1-worm and the 4-worm groups, leaving $12 \mathrm{Ss}$ in each of these groups.) A repeated-measures analysis of variance yielded significant effects of groups $(F=3.3, \mathrm{df}=2 / 35, \mathrm{p}<.05)$ and of blocks $(\mathrm{F}=55.3, \mathrm{df}=7 / 245$, p <.01), but not of the Groups by Blocks interaction $(F<1)$. The significant groups effect was due primarily to the difference between the 1 -worm and the 40 -worm groups (for an orthogonal comparison of these two groups, $\mathrm{F}=6.7$, $\mathrm{df}=1 / 35$ $p<.01$ ); Scheffé (1953) tests showed that the 4-worm group did not differ significantly from either of the other two. In extinction, the performance of the groups was closely related to their performance in acquisition, the differences among the groups in terminal levels of acquisition being essentially preserved throughout extinction. A repeated-measures analysis of variance yielded precisely the same pattern of outcomes as in acquisition: the effects of groups ( $F=$ $4.0, \mathrm{df}=2 / 35, \mathrm{p}<.05)$ and of blocks $(\mathrm{F}=7.1, \mathrm{df}=12 / 420, \mathrm{p}<.01)$ were significant; their interaction was not. An orthogonal comparison and Scheffé tests also yielded the same outcomes as in acquisition: the difference between the 1 -worm and the 40 -worm groups was significant ( $F$ $=7.9, \mathrm{df}=1 / 35, \mathrm{p}<.01)$; the other differences were not.

The positive relation between amount of reward and resistance to extinction obtained here confirms for a locomotor response under spaced trials conditions the results of the earlier experiments for a manipulative response under massed trials and free operant conditions (Gonzalez \& Bitterman, 1967; Gonzalez et al, 1967).

\section{EXPERIMENT 2}

In the experiment now to be reported, the conventional depression effect was sought in goldfish trained under the conditions of Experiment 1 which yielded functionally distinct magnitudes of reward. In all, there were four groups of fish given one trial per day in the runway: Group 1-1 was reinforced throughout with 1 worm Group 40.40 was reinforced throughout with 40 worms: Group 40-1 was reinforced with 40 worms and then downshifted to 1 worm; Group 40-0 was reinforced with 40 worms and then downshifted to no worms. Although Experiment 1 demonstrated that fish extinguish readily in this situation, the extinction group (40-0) was added to the design to afford a direct comparison of the effects of complete and incomplete reduction in amount of reward. Group 40-40 was added to provide a basis for determining whether the downshift to 1 worm produced any decrement at all in the performance of Group 40-1.

\section{Subjects and Apparatus}

The Ss were 60 experimentally naive goldfish, 4.5 in. long, obtained from a local dealer. They were housed and maintained in the same mannel as Ss of Experiment 1. The apparatus was the same as that used in Experiment 1. Procedure

After adjustment to the laboratory and to handling, the Ss were given 3 the goal compartment by the same procedure as in Experiment 1. Each such feeding consisted of 1 worm for 15 randomly selected Ss (Group 1-1) and of 40 worms for the remaining 45 Ss. days of direct placement feedings in
In the first (preshift) stage of the experiment proper, which lasted 30 days, each $\mathbf{S}$ was given one reinforced trial per day in the runway. Group 1-1 was reinforced with 1 worm; the remaining Ss were reinforced with 40 worms. The procedure on each trial was identical to that used in Experiment 1. On the basis of their performance over the 30 days of Stage 1, the 40-worm animals were divided into three matched groups of 15 Ss each: Group 40-40, Group 40-1, and Group 40-0.

The second (postshift) stage of the experiment lasted 33 days. On each trial, the Ss of Groups 1-1 and 40-1 were reinforced with 1 worm; the $\mathrm{Ss}$ of Group 40-40 continued to be reinforced with 40 worms; and the Ss of Group 40-0 were given no worms (the procedure was identical to the extinction procedure of Experiment 1). If, on any trial, $S$ did not reach the goal compartment in $3 \mathrm{~min}$, the trial was terminated and $\mathrm{S}$ was returned to its home tank. As in Experiment 1, the total daily intake of food for each $S$ consisted of 42 worms and a small quantity of dry food. Results

In Fig. 2, mean log total time on the last three-trial block of preshift training (T) and on each of the 12 three-trial blocks of postshift training is shown for each of the four groups. (The data are based on 15, 14, 14, and 13 Ss in Groups 1-1, 40-40, 40-0, and 40-1, respectively, four animals having been lost in the course of the experiment.) As in Experiment 1, 40 worms produced superior performance to 1 worm in the first stage of the experiment. A repeated-measures analysis of variance for the entire course of preshift training yielded significant effects of groups $(F=5.5$, df $=3 / 52, p<.01$ ), of trial blocks ( $F$ $=68.9, \mathrm{df}=9 / 468, \mathrm{p}<.01)$, and of the Groups by Blocks interaction $(\mathrm{F}=$ 15.1, df $=27 / 468, \quad p<.01)$. Subsequent orthogonal comparisons showed that the 1-worm group differed significantly from the 40 -worm groups ( $F=16.5, \mathrm{df}=1 / 52$, $p<.01$ ), which did not differ from each other $(F<1)$. The postshift curves suggest that 40 worms as compared with 1 worm continued to maintain superior performance, that the shift from 40 worms to 1 worm produced no measurable change in performance, and that the shift from 40 worms to no worms produced substantial extinction. These impressions were substantiated by a repeated-measures analysis of variance and by subsequent orthogonal comparisons. (For groups, $\mathrm{F}=6.3 \mathrm{df}$ $=3 / 52, \mathrm{p}<.01$; for trial blocks, $\mathrm{F}=$ $10.1, \mathrm{df}=11 / 572, \mathrm{p}<.01 ;$ for the Groups by Blocks interaction, $\mathrm{F}=2.9$, 
$\mathrm{df}=33 / 572, \quad \mathrm{p}<.01$. For an orthogonal comparison of Group 40-0 with the other three groups combined, $F=12.5, \mathrm{df}=1 / 52, \mathrm{p}<.01$; for Group 1-1 vs Groups $40-40$ and $40-1$ combined, $F=4.01, \mathrm{df}=1 / 52, \mathrm{p}=$ .05 ; for Group 40-40 vs Group 40-1, $\mathrm{F}<1$.) These analyses are based on total time measures, and it might be well to note that of the three component measures, the first (start time) was least sensitive and the last (goal time) was most sensitive both to the effects of amount of reward on asymptotic performance and to the effects of extinction. None, however, offered any information not contained in the total time measure, which was the most stable and the only one presented here in the interest of conserving space.

This experiment, then, gives no indication of a depression effect in fish. As was the case in an earlier experiment on the problem (Lowes \& Bitterman, 1967), but here under conditions analogous to those which are most favorable for producing the effect in rats, the shift from large to small reward produced no measurable decrement in performance. The present results go beyond the earlier ones also in showing this lack of performance decrement against the performance of an unshifted control group and over a time course sufficient to yield substantial extinction in fish downshifted to zero reward. DISCUSSION

In free operant situations and in discrete trials, with massed as well as with spaced practice, the relation between resistance to extinction and amount of reward is a direct one for fish and an inverse one for rats. The inverse relation appears to be the product of contrast, and the failure of fish also to show the depression effect is in accord with this view. Mackintosh (1971) recently has confirmed both sets of runway results for goldfish in massed trials. Another recent experiment on incentive shift in goldfish failed, unfortunately, to yield interpretable results because of several serious deficiencies (Raymond, Aderman, \& Wolach, 1972). The most obvious, perhaps, is that the stimulus properties of food were confounded with its reinforcing properties - the food used on each trial was at the end of the runway when the trial began and clearly visible to the animal before completion of the measured response.

The differences between fish and rats which have appeared in these types of experiment suggest that reward plays a different role in the instrumental learning of the two animals. The behavior of the fish follows from a strict principle of reinforcement ('Thorndike, 1911; Hull,

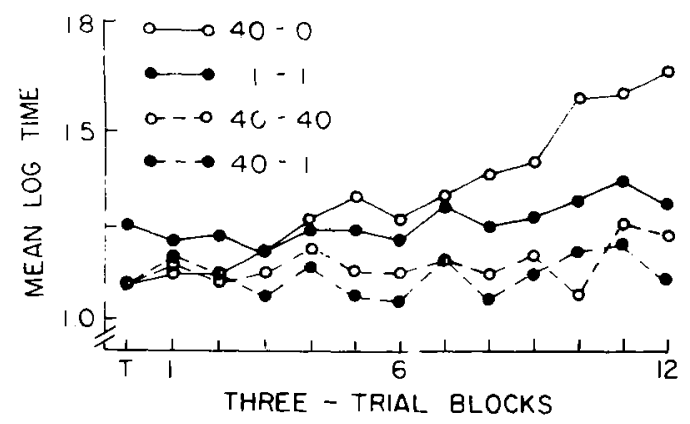

Fig. 2. The effects of complete and incomplete reduction in amount of reward. (The $T$ represents the last three-trial block of preshift training.)

1943), according to which reward operates directly to establish and strengthen the tendency to respond in a given situation. Since, in these terms, large as compared with small rewards produce stronger connections and resistance to extinction increases with the strength of connection, it follows that resistance to extinction should vary directly with amount of reward. In a Crespi experiment, an upward shift in amount of reward should, of course, improve performance, because the increase in amount of reward produces an increase in the strength of connection. A shift from large to small reward should yield continued improvement in performance (although at a lesser rate than continued training with large reward), at least to the point in training at which the strength of connection reaches the asymptote for the small reward. If, however, the preshift training is continued beyond that point (as was the case in Experiment 2), a subsequent downshift in amount of reward cannot affect performance because a stronger connection than that which the small reward is capable of producing already will have been developed.

In rats, reward seems to play a different role-that of an incentive. Rather than acting to strengthen behavior directly, rewards seem to function as anticipated consequences of response to translate the products of learning into behavior. This view of the role of reward in the control of instrumental behavior, espoused earlier by Tolman (1932) and influenced strongly by Crespi's results for rats, finds wide acceptance in a variety of forms among contemporary theorists. The inverse relation between resistance to extinction and amount of reward, like the depression effect, commonly is assumed to be mediated by an emotional process (Amsel, 1958) engendered by the change in amount of reward-the larger the anticipated amount of reward, the greater the emotional reaction and the consequent disruption of performance.

AMSEL, A. The role of frustrative nonreward in noncontinuous reward situations. Psychological Bulletin, 1958, 55, 102-119.

CRESPI, L. E. Quantitative variation of incentive and performance in the white rat. American Journal of Psychology, 1942, 55, 467-517.

DENNY, $M$. R. One bar-press per day: Acquisition and extinction. Journal of the Experimental Analysis of Behavior. $1959,2,81-85$

GONZALEZ, R. C., \& BITTERMAN, M. E. $P$ artial reinforcement effect in the goldfish as a function of amount of reward. Journal of Comparative \& Physiological Psychology, 1967, 64, 163-167.

GONZALEZ, R. C., \& BITTERMAN, M. E. Spaced-trials partial reinforcement effect as a function of contrast. Journal of Comparative \& Physiological Psychology, $1969,67,94-103$.

GONZALEZ, R. C., HOLMES, N. K., \& BITTERMAN, M. E. Resistance to extinction in the goldfish as a function of frequency and amount of reward. American Journal of Psychology, 1967. 80, 269-275.

HULL, C. L. Principles of behavior. New York: Appleton-Century-Crofts, 1943.

HULSE, S. H., JR. Amount and percentage of reinforcement and duration of goal confinement in conditioning and extinction. Journal of Experimental Psychology, 1958, 56, 48-57.

LOWES, G., \& BITTERMAN, M. E. Reward and learning in the goldfish. Science, $1967,157,455-457$.

MACKINTOSH, N. J. Reward and aftereffects of reward in the learning of goldfish. Journal of Comparative \& Physiological Psychology, 1971, 76, 225-232.

POTTS, A., \& BITTERMAN, M. E. A runway for the fish. Behavior Research Methods \& Instrumentation, 1968, 1 , 26-27.

RAYMOND, B., ADERMAN, M., \& WOLACH, A. H. Incentive shifts in goldfish. Journal of Comparative \& Physiological Psychology, 1972, 78, 10-13.

SCHEFFÉ, H. A. A method for judging all possible contrasts in the analysis of variance. Biometrika, 1953, 40, 87-104.

THORNDIKE, E. L. Animal intelligence New York: Macmillan. 1911.

TOLMAN, C. Purposive behavior in animals $a n d m e n . \quad \mathrm{N} w \quad \mathrm{Y}$ o $\mathbf{k}$ : Appleton-Century-Crofts, 1932.

WAGNER, A. R. Effects of amount and percentage of reinforcement and number of acquisition trials on conditioning and extinction. Journal of Experimental Psychology, 1961, 62, 234-242. 